\title{
Technical note: The development of a methodology for ruminal and colon tissue biopsying of young Holstein dairy calves
}

\author{
J. K. van Niekerk, ${ }^{*}$ M. Middeldorp, $†$ and M. A. Steele ${ }^{* 1}$ \\ *Department of Agricultural, Food and Nutritional Science, University of Alberta, Edmonton, AB, T6G 2P5, Canada \\ †Animal Nutrition Group, Wageningen University and Research, Wageningen $6700 \mathrm{AH}$, the Netherlands
}

\begin{abstract}
The objectives of this study were to develop a methodology for biopsying the rumen and colon of young dairy calves and to collect suitable quality tissue samples for microscopic and gene expression analysis. Six Holstein dairy bull calves $(45.0 \pm 1.5 \mathrm{~kg}$ birth weight) were ruminally cannulated during the second week of life and weaned at the end of wk 6 . Ruminal and colon tissue samples were collected at the end of wk 5, 6, 7, 8 , and 12. Calves were not sedated but were restrained in a chute for sampling. The endoscope $(100 \mathrm{~cm}$ length, $9.8 \mathrm{~mm}$ diameter) was introduced through the rumen cannula to harvest ruminal tissue. Endoscopic biopsies of the rumen with endoscopic biopsy forceps were unsuccessful $85 \%$ of the time because they were unable to shear the ruminal tissue. Thereafter, an Allis clamp was used to retrieve the blind sac through the rumen cannula to perform direct tissue biopsying with surgical scissors. To biopsy the colon, the lubricated distal tip of an endoscope was slowly inserted into the calf's anus. A total of 6 colon tissue samples $(12.6 \pm 0.74 \mathrm{mg})$ were collected per calf per time point from the distal colon 30 to $40 \mathrm{~cm}$ from the calf's anus using endoscopic biopsy forceps, which were inserted through the instrument channel. A new forcep was used between sites and calves. Between calves, the outside of the endoscope was washed with $4 \%$ chlorohexidine and rinsed with water and the instrument channel was washed with distilled water and $70 \%$ ethanol. Colon and ruminal samples were processed for histological measurements, and RNA was isolated and sequenced. High-quality RNA (RNA integrity number $8.8 \pm 0.08$ ) was collected from samples, and light and electron microscopy was performed on samples. In conclusion, endoscopic biopsying can be used for tissue harvest in the colon of young calves. However, it was found that collecting ruminal
\end{abstract}

Received January 2, 2018.

Accepted March 31, 2018

${ }^{1}$ Corresponding author: masteele@ualberta.ca tissue by retracting the rumen from the cannula and taking samples with surgical scissors was more successful than an endoscopic biopsy. This method allows for tissue collection of the same animal throughout time, which can help the research community investigate the effect of weaning regimens, feed rations, and age on the structure and function of the gastrointestinal tract.

Key words: endoscopic biopsy, colon, rumen, microscopy

\section{Technical Note}

The gastrointestinal tract (GIT) is of great importance in dairy production systems because it is involved in many biological processes and its function and health can be easily influenced by both internal and external factors. The GIT has multiple roles that include, but are not limited to, absorption, metabolism, nutrient delivery, and barrier function (Steele et al., 2016). Young calves experience dramatic structural and metabolic adaptations of the GIT. It has been reported that weaning increases GIT permeability (Wood et al., 2015) and negatively influences cell-mediated and humoral immunity of calves (Mackenzie et al., 1997; Hickey et al., 2003) and therefore may lead to increased health risks for calves. The effect of weaning on the rumen has been researched extensively, but little is known about its effect on the lower gut.

Gastrointestinal tract development of the calf has been reported in multiple publications using serial slaughtering (Warner et al., 1956; Lane et al., 2002). However, this approach is not ideal to study temporal responses because the sampling time point for the animal is limited to 1. Large variations also exist among animals, and repeated measurements can increase statistical power, reduce animal numbers, and reduce the time it takes to conduct the research given that fewer animals need to be recruited (Dell et al., 2002). Developing a method to collect GIT tissue in the same animal throughout time using an endoscope will enable researchers to investigate the effect of weaning regimens, feed rations, and age on the GIT postweaning as well as long-term responses. 
Ruminal cannulation remains the best approach to access the rumen because it is minimally invasive and allows for long-term, sequential sampling (Hecker, 1969). However, cannulation can be a limitation when large numbers of animals are required. Ruminal tissue is normally obtained by partially evacuating the ventral sac, retracting the ventral sac to the cannula, and then clipping the ruminal tissue using surgical scissors (Steele et al., 2011). As an alternative approach, McRae et al. (2016) introduced an endoscope through the esophagus of sedated, noncannulated sheep in a dorsally recumbent position at $45^{\circ}$ with the head upright. They were able to biopsy the anterioventral region of the rumen using single-use biopsy forceps in sheep fasted for 4 or 24 h. Furthermore, Sasikala et al. (2017) reported that when endoscopic biopsying of the reticulum was attempted via the nasal route in nonsedated but restrained cattle, the cattle tolerated the procedure well and biopsies were successful. However, they also reported that it was possible to visualize the reticular mucosal surface only after $36 \mathrm{~h}$ of fasting, which is a limitation given that it may influence performance and other metabolic processes the study may be evaluating. Ultimately, both methods (McRae et al., 2016; Sasikala et al., 2017) have disadvantages when access to the ruminal epithelium for long-term sequential sampling is desired due to either sedation or fasting.

Endoscopic biopsy of the colon is commonly performed in humans to diagnose intestinal diseases such as intestinal tuberculosis (Kim et al., 1998) and cancer (e.g., Lieberman et al., 2000; Schoenfeld et al., 2005) as well as in companion animals (e.g., cats, dogs) to diagnose intestinal diseases (Washabau et al., 2010). Histology is also used to examine the tissue samples obtained via endoscopy because it allows for a more precise diagnosis, especially in inflammatory and neoplastic diseases in humans (Geboes et al., 2013) and companion animals (Washabau et al., 2010). However, currently no data or literature exist around endoscopic biopsying of the colon of ruminants to investigate development throughout time. Thus, the primary objective of this study was to develop a methodology for biopsying the rumen and colon of young dairy calves. The secondary objective was to determine whether the samples were suitable for microscopic and gene expression analysis.

To meet our objectives, 6 Holstein dairy bull calves (45 $\pm 1.5 \mathrm{~kg}$ birth weight) were obtained from a commercial dairy farm and housed in individual pens at the Metabolic Unit, University of Alberta, Edmonton, Canada. The calves were cared for and handled in accordance with the Canadian Council on Animal Care (CCAC, 2009) regulations, and the institutional Animal Care and Use Committee approved all experimental procedures (UCACS protocol no. 00002010). Calves received colostrum replacer the first day of life and then 3 $\mathrm{L}$ of milk replacer solution twice daily for the first week of life. From the second week onward, milk replacer was fed according to $15 \%$ of $\mathrm{BW} / \mathrm{d}$ in 2 equal volumes twice daily. During weaning, calves were restricted to $50 \%$ of milk for wk 6 and fully weaned at the end of wk 6 . Texturized calf starter $(23.4 \% \mathrm{CP}, 4.5 \%$ crude fat, $15.1 \% \mathrm{NDF}, 9.3 \% \mathrm{ADF}$ ), straw $(4.1 \% \mathrm{CP}, 1.0 \%$ crude fat, $75.7 \% \mathrm{NDF}, 53.9 \% \mathrm{ADF}$ ), and water was offered ad libitum at $0700 \mathrm{~h}$ and when required at 1900 h. In the second week of life, all calves were fitted with rubber ruminal cannulas $(2.8 \mathrm{~cm}$ diameter; Lesmeister and Heinrichs, 2004).

Ruminal and colon tissue biopsies were taken at the end of wk $5,6,7,8$, and 12 . The calves were not sedated but were restrained in a calf chute during sampling. For ruminal tissue sampling, the distal tip of the endoscope (100 cm length, $9.8 \mathrm{~mm}$ diameter; GIF-Q140, Olympus, Tokyo, Japan) connected to a light source and processor (CLV-U40 and CV-140, Olympus) was introduced into the rumen through the cannula. The biopsy was attempted at the blind sac (Figure 1A) using Captura hot biopsy forceps (Figure 2B; $2.4 \mathrm{~mm}$ diameter; HDBF-2.4-230-S, Cook Medical, Bloomington, IN). The blind sac was the chosen site of sampling because it could be visualized with the endoscope; the other sites were submerged with digesta. Sampling without visualization of the biopsy site was not attempted because the pressure of the endoscope or forcep against the tissue risked puncturing through the tissue. With 5 attempts using the Captura hot biopsy forceps, samples could be collected only $15 \%$ of the time. Alternatively, alligator jaws with needle biopsy forceps $(2.4 \mathrm{~mm}$ diameter; DBF-2.4-230SP-S, Cook Medical) were used to attempt sampling the blind sac. Five sampling attempts were made per calf per forcep type. The outside of the endoscope was washed with $4 \%$ chlorohexidine and rinsed with water between calves. The instrument channel was washed with double distilled water and $70 \%$ ethanol between calves. Both endoscopic biopsy forceps were able to excise the rumen epithelium only $15 \%$ of the time, which we suspect is due to strong connective tissue. Even though the success rate was low using endoscopic biopsying in the rumen, it still can be used as a means of tissue sampling in live animals (McRae et al., 2016; Sasikala et al., 2017). Franz et al. (2006) used an endoscope for visualization of the rumen in calves that were fasted for $12 \mathrm{~h}$ via a rumen cannula and through the esophagus. The authors reported that when the endoscope was introduced through the esophagus in nonsedated calves, it failed in 3 of 9 calves because the calves moved too much. In addition, even though the calves were fasted for $12 \mathrm{~h}$, visualization of 
the ventral sac and the caudoventral blind sac was not possible due to rumen fill when the endoscope was introduced through the esophagus. Thus, biopsying of the ventral sac and the caudoventral blind sac would not be possible due to compromised visualization and the increased possibility of tissue damage. More recently, it was shown that animals may need to be fasted (Sa- sikala et al., 2017) or sedated and placed in a dorsally recumbent position (McRae et al., 2016) to obtain a visual of the area that would be sampled. However, this process is not ideal in studies where long-term and frequent sampling is required given that fasting animals can influence performance and other metabolic processes (Keogh et al., 2015).
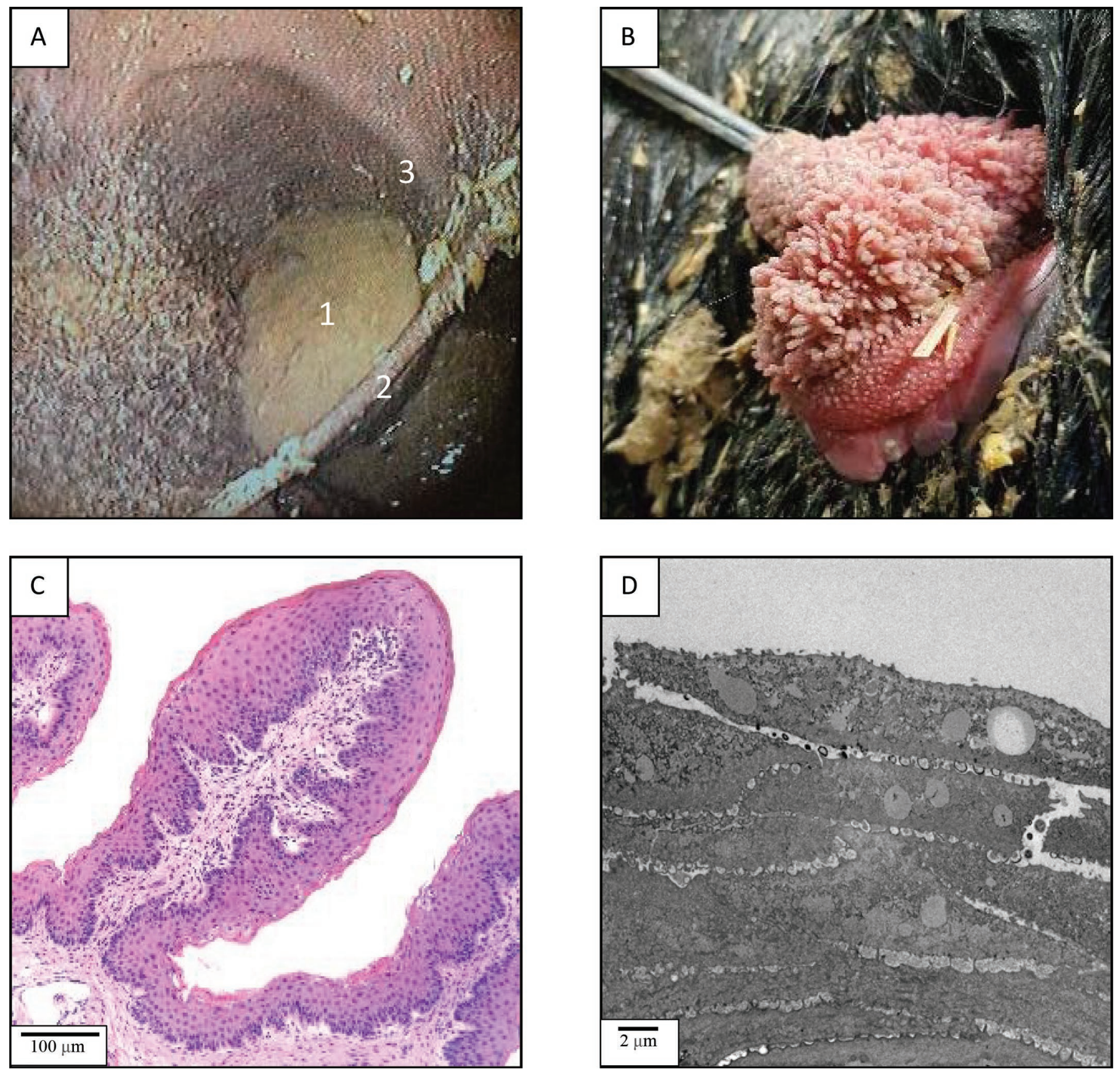

Figure 1. (A) Photograph of the caudodorsal blind sac (1), caudal pillar (2), and dorsal coronary pillar (3) of the rumen. (B) The dorsal coronary pillar retrieved through the cannula hole using Allis clamps. (C) Image from rumen papillae at wk 7 under the light microscope. (D) Image of strata in rumen papillae under the transmission electron microscope. Color version available online. 

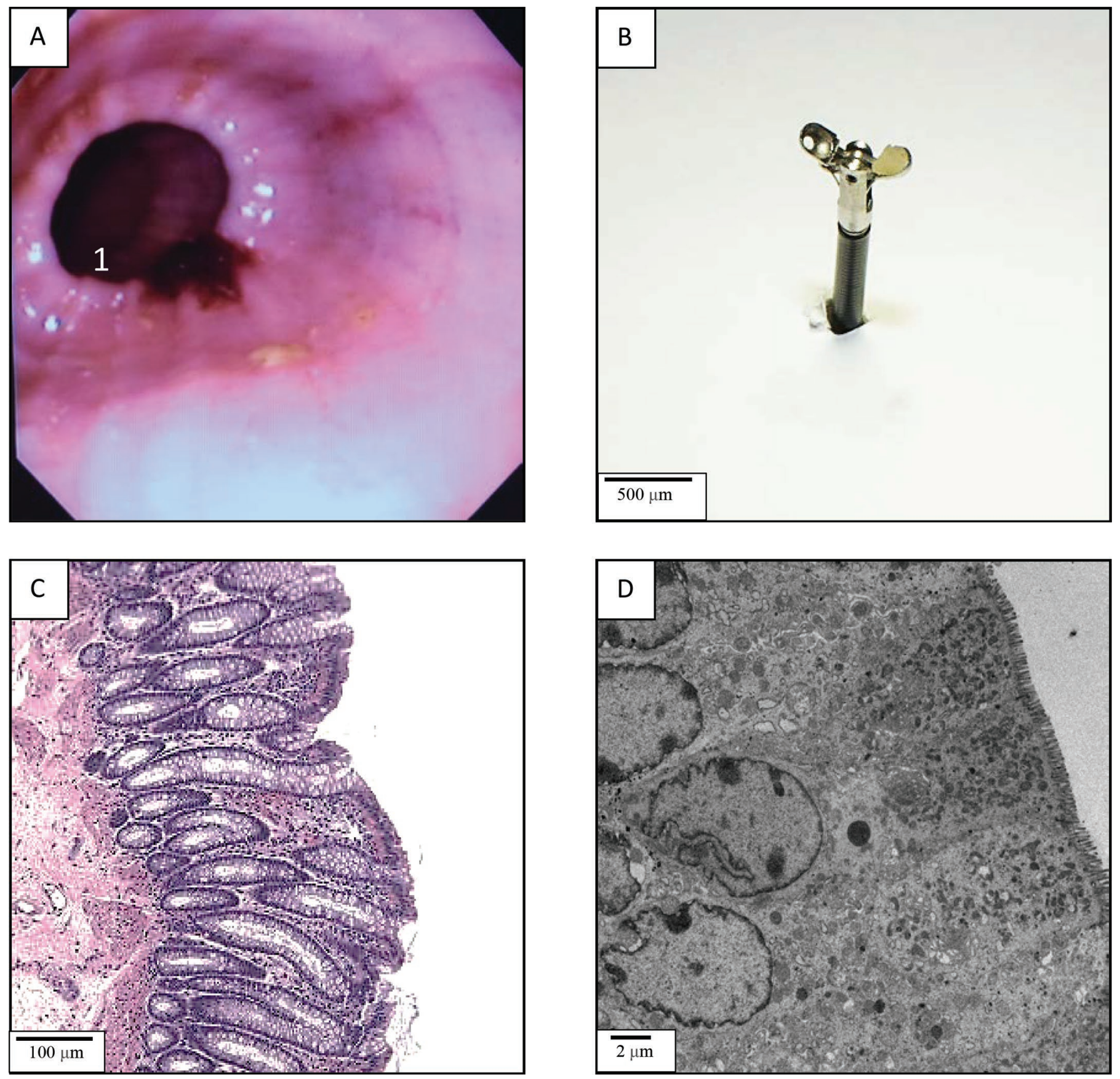

Figure 2. (A) Photograph of the colon $40 \mathrm{~cm}$ from the calf's anus. As shown, sampling resulted in minimal bleeding (1). (B) Image of colon tissue sample in the biopsy forcep. (C) Image of colon mucosa under the light microscope. (D) Image of the colon under the transmission electron microscope. Color version available online.

After using the endoscope, it was determined that an alternative methodology to harvest ruminal tissue should be considered. To meet this objective, the cannula was removed from the animal and $\mathrm{OB}$ caesarean forceps (30 cm; Jorvet, Loveland, CO) were used to attempt retraction of the ventral sac of the rumen through the cannula. During wk 5 and 6 the OB cae- sarean forceps could grip onto the ventral sac, but the grip was lost once retraction was attempted. It also was not possible to grip onto the ventral sac in wk 7, 8, and 12. Alternatively, the dorsal coronary pillar (Figure 1A) was retrieved through the cannula opening using Allis clamps (15 cm; Jorvet; Figure 1B), exposing the caudodorsal blind sac for sampling. By wk 12 
(6 wk after weaning) it became necessary to evacuate half of the rumen contents with a vacuum due to rumen fill, which made the rumen too heavy to retract through the cannula. All rumen contents were replaced after sampling. Four biopsy tissue samples (16.1-136.3 $\mathrm{mg}$ wet weight) were collected from the caudodorsal blind sac with surgical scissors. Ruminal tissue sample weight increased as the calves got older because the papillae increased in size. The ruminal tissue samples were washed in PBS once obtained. Two ruminal tissue samples were submerged in $10 \%$ formalin solution and stored at room temperature for histological analysis. An additional 2 ruminal tissue samples were stored in RNA stabilization fluid (RNALater, ThermoFisher Scientific, Burlington, ON, Canada) at room temperature for $24 \mathrm{~h}$ and then frozen at $-20^{\circ} \mathrm{C}$ for later extraction of RNA. Rumen papillae dimensions were obtained by retrieving the rumen tissue from the fixative (formalin) and submerging it in PBS. When necessary, a row of subsequent papillae or individual papillae (depending on size) was dissected. For histological measurements, ruminal tissue samples were dehydrated overnight, submerged in paraffin wax, sectioned in $4-\mu$ m-thick slices, and stained with hematoxylin and eosin (Steele et al., 2011). The papillae were imaged with a magnification of $10 \times$ and $20 \times$ using a light microscope (Zeiss Axio Scope.A1, Oberkochen, Germany) and optronics digital camera (PictureFrame version 2.3, Optronics, Goleta, $\mathrm{CA}$; Figure 1C). These images were of suitable quality to measure the thickness of the epithelium, corneum, granulosum, spinosum, and basal layer as well as the number of cells per layer using ImageJ (National Institutes of Health, Bethesda, MD). Ruminal tissue samples were also prepared for transmission electron microscopy and examined using a transmission electron microscope (Morgagni 268, Philips FEI, Hillsboro, OR; Figure 1D). Our success with microscopic analysis is in agreement with Sasikala et al. (2017), who reported that biopsy tissue from the reticulum revealed muscularis mucosae, which indicates that endoscopic biopsy tissue from the reticulum can be used for histological measurements.

The total RNA was isolated from each sample (average total RNA harvest was 12,958 $\pm 1,013 \mathrm{ng}$ ) using an RNeasy mini kit (Qiagen Inc., Germantown, MD) and assessed for RNA quality. The mean RNA integrity number (RIN; Agilent 2200 TapeStation, Agilent Technologies, Santa Clara, CA) for the ruminal tissue samples was $8.9 \pm 0.13$. The reported RIN is of similar or higher quality than when ruminal tissue was obtained through slaughtering (RIN $8.4 \pm 0.7$, Connor et al., 2013) and when samples were obtained from the rumen using endoscopic biopsying (RIN 6.3-8.2; McRae et al., 2016). Total RNA was used to construct the library with a unique index, and the individual indexed libraries were then pooled and sequenced on the IlluminaHiSeq 4000 system (Illumina, Toronto, ON, Canada). Sequencing reads were aligned to the reference bovine genome (UMD 3.1; Zimin et al., 2009), and read counts were obtained based on the annotation from Ensembl bovine gene annotation. Total detectable genes expressed in the rumen tissue samples were $14,636,14,556$, and 14,737 in wk 5,7 , and 12 , respectively, which is similar to other reports from rumen tissue collected from 11-wk-old calves (Kim et al., 2016).

Collecting ruminal tissue through retraction of the rumen and sampling with surgical scissors was more successful than using the endoscopic biopsy method. However, differences between regions of the rumen were found in previous studies (Roth et al., 2009) and may be a limitation when endoscopic biopsying is used and visualization is impaired. In noncannulated animals, sedation and fasting (McRae et al., 2016; Sasikala et al., 2017) may aid in endoscopic biopsying, but frequent sedation and fasting might influence performance and other metabolic processes, thereby hindering accurate results (Keogh et al., 2015). In small animals such as calves, the cannula is small $(2.8 \mathrm{~cm}$ diameter $)$, thus limiting the use of instruments to retract the ventral sac to sample other regions of the rumen. Using a cannula allows the rumen to be emptied, making endoscopic biopsying through the cannula a more effective option because different regions can be sampled and the rumen contents can be returned to the rumen. It might also be possible to collect density measurements of rumen papillae in live animals that have been ruminally cannulated. Nevertheless, collecting ruminal tissue through retraction of the rumen and sampling with surgical scissors or biopsying tissue with the endoscope can enable repeated measures, resulting in fewer animals required for studies (Dell et al., 2002).

The next objective of our study was to obtain colon tissue samples using the same endoscope, light source, and processor as previously described. The lubricated distal tip of the endoscope was gradually inserted into the calf's anus. Six colon tissue samples $(12.6 \pm 0.74$ $\mathrm{mg} / \mathrm{sample})$ were collected per calf per time point from the distal colon $(30-40 \mathrm{~cm}$ from the calf's anus; Figure 2A) with endoscopic biopsy forceps (Figure 2B; Captura hot biopsy forceps, HDBF-2.4-230-S, Cook Medical), which were inserted through the instrument channel. The distal part of the colon was the targeted site of sampling, although it is possible to sample various parts of the lower GIT. For example, in human medicine, sampling of the terminal ileum is frequently used to provide information regarding inflammatory diarrhea in patients (Geboes et al., 2013). The instrument channel and endoscope were washed as described 
above. Two samples were taken for microscopic analysis and 4 samples were taken for extraction of RNA (average total RNA harvest was 9,961 $\pm 662 \mathrm{ng} /$ sample) per calf per time point. The colon tissue samples were processed for histology and ultrastructure analysis using the same approach as the ruminal tissue samples (Figure 2C and D).

The colon tissue samples had a mean RIN of $8.7 \pm$ 0.09. Total detectable genes expressed in the colon tissue samples were $15,173,15,085$, and 15,149 at wk 5 , 7 , and 12 , respectively. From the colon tissue samples obtained, 45 out of 60 contained muscularis mucosa, which indicates that samples were viable for histological measurements of the outer mucosa (Figure 2C). In human medicine, the average diameter of forceps used is $2.4 \mathrm{~mm}$, and $60 \%$ of these samples contain muscularis mucosa (and upper submucosa; Geboes et al., 2013). Additionally, the larger forceps have a diameter of 3.4 $\mathrm{mm}$, meaning that the tissues obtained are larger but usually do not contain increased submucosa. Moreover, the larger forcep boasts a higher risk of complications compared with the smaller forcep used in this study.

It was thought that the amount of tissue sampled in each biopsy attempt would not be sufficient for histological and ultrastructural analysis. Based on the micrographs collected from our samples (Figure 2C and $\mathrm{D})$, it is feasible to use this technique to investigate the effect of weaning regimens, feed rations, and age on the GIT postweaning as well as long-term effects on colon tissue structure and function. When attempting tissue biopsying of the colon, there was some initial concern around the damage caused by taking a large number of samples. In human medicine, Magro et al. (2013) reported that when ulcerative colitis is suspected, biopsies should be obtained at $10-\mathrm{cm}$ intervals, and 6 to 10 samples are required from different sites. Rubin et al. (1992) removed 68 shallow biopsy samples $(5 \mathrm{~mm})$ with spiked "jumbo" forceps throughout the intestines of patients with dysplasia and concluded that 56 biopsy samples are needed to ensure a $95 \%$ confidence level. After investigating routine procedures in human medicine, it was determined that the number of samples taken in the current study is within a very conservative number range.

Collecting colon tissue through endoscopic biopsying in the same animal throughout time means that fewer animals are required for studies (Dell et al., 2002). Sampling the distal colon in nonsedated but restrained animals was successful and would allow other parts of the small intestine to be sampled through the rectum. However, these animals may require sedation for this procedure, which could influence performance and other metabolic processes. Alternatively, full-body re- straint of the animals may provide a suitable substitute to sedation.

In summary, we found that collecting ruminal tissue by retracting the rumen through the cannula and sampling with surgical scissors was more successful than using the endoscopic biopsy method in young calves. Endoscopic biopsying from the colon in young, nonsedated, and restrained calves is possible. The ruminal tissue samples that were excised with surgical scissors and the colon tissue samples obtained via endoscopic biopsy both resulted in high-quality samples suitable for microscopic and gene expression analysis.

\section{ACKNOWLEDGMENTS}

The authors thank Natural Sciences and Engineering Research Council of Canada (NSERC), Alberta Milk (Edmonton, AB, Canada), Lallemand (Montreal, QC, Canada), Westgen (Abbotsford, BC, Canada), BC Dairy Association (Burnaby, BC, Canada), SaskMilk (Regina, SK, Canada), and the Dairy Farmers of Manitoba (Winnipeg, MB, Canada) for the financial support provided for this study.

\section{REFERENCES}

CCAC. 2009. Guidelines on: The Care and Use of Farm Animals in Research, Teaching and Testing. Canadian Council on Animal Care, Ottawa, ON, Canada.

Connor, E. E., R. L. Baldwin, C.-J. Li, R. W. Li, and H. Chung. 2013. Gene expression in bovine rumen epithelium during weaning identifies molecular regulators of rumen development and growth. Funct. Integr. Genomics 13:133142.

Dell, R. B., S. Holleran, and R. Ramakrishnan. 2002. Sample size determination. ILAR J. 43:207-213.

Franz, S., A. Gentile, and W. Baumgartner. 2006. Comparison of two ruminoscopy techniques in calves. Vet. J. 172:308-314.

Geboes, K., K. Geboes, and A. Jouret-Mourin. 2013. Endoscopy and histopathology. Accessed Apr. 19, 2018. https://www.intechopen .com/books/endoscopy/endoscopy-and-histopathology.

Hecker, J. F. 1969. A simple rapid method for inserting rumen cannulae in sheep. Aust. Vet. J. 45:293-294.

Hickey, M. C., M. Drennan, and B. Earley. 2003. The effect of abrupt weaning of suckler calves on the plasma concentrations of cortisol, catecholamines, leukocytes, acute-phase proteins and in vitro interferon-gamma production. J. Anim. Sci. 81:2847-2855.

Keogh, K., S. M. Waters, A. K. Kelly, A. R. G. Wylie, H. Sauerwein, T. Sweeney, and D. A. Kenny. 2015. Feed restriction and realimentation in Holstein-Friesian bulls: II. Effect on blood pressure and systemic concentrations of metabolites and metabolic hormones. J. Anim. Sci. 93:3590-3601.

Kim, K. M., A. Lee, K. Y. Choi, K. Y. Lee, and J. J. Kwak. 1998. Intestinal tuberculosis: Clinicopathologic analysis and diagnosis by endoscopic biopsy. Am. J. Gastroenterol. 93:606-609.

Kim, Y. H., N. Toji, K. Kizaki, S. Kushibiki, T. Ichijo, and S. Sato. 2016. Effects of dietary forage and calf starter on ruminal $\mathrm{pH}$ and transcriptomic adaptation of the rumen epithelium in Holstein calves during the weaning transition. Physiol. Genomics 48:803-809.

Lane, M. A., R. T. Baldwin, and B. W. Jesse. 2002. Developmental changes in ketogenic enzyme gene expression during sheep rumen development. J. Anim. Sci. 80:1538-1544. 
Lesmeister, K. E., and A. J. Heinrichs. 2004. Effects of corn processing on growth characteristics, rumen development, and rumen characteristics in neonatal dairy calves. J. Dairy Sci. 87:3439-3450.

Lieberman, D. A., D. G. Weiss, J. H. Bond, D. J. Ahnen, H. Garewal, W. V. Harford, D. Provenzale, S. Sontag, T. Schnell, T. E. Durbin, and D. B. Nelson. 2000. Use of colonoscopy to screen asymptomatic adults for colorectal cancer. N. Engl. J. Med. 343:162-168.

Mackenzie, A. M., M. Drennan, T. G. Rowan, J. B. Dixon, and S. D. Carter. 1997. Effect of transportation and weaning on humoral immune responses of calves. Res. Vet. Sci. 63:227-230.

Magro, F., C. Langner, A. Driessen, A. Ensari, K. Geboes, G. J. Mantzaris, V. Villanacci, G. Becheanu, P. B. Nunes, G. Cathomas, and W. Fries. 2013. European consensus on the histopathology of inflammatory bowel disease. J. Crohns Colitis 7:827-851.

McRae, K. M., M. Schultz, C. G. Mackintosh, G. H. Shackell, M. F. Martinez, K. J. Knowler, M. Williams, C. Ho, S. N. Elmes, and J. C. McEwan. 2016. Ovine rumen papillae biopsy via oral endoscopy; A rapid and repeatable method for serial sampling. N. Z. Vet. J. 64:174-178.

Roth, B. A., N. M. Keil, L. Gygax, and E. Hillmann. 2009. Influence of weaning method on health status and rumen development in dairy calves. J. Dairy Sci. 92:645-656.

Rubin, C. E., R. C. Haggitt, G. C. Burmer, T. A. Brentnall, A. C. Stevens, D. S. Levine, P. J. Dean, M. Kimmey, D. R. Perera, and P. S. Rabinovitch. 1992. DNA aneuploidy in colonic biopsies predicts future development of dysplasia in ulcerative colitis. Gastroenterology 103:1611-1620.

Sasikala, K., G. Vijayakumar, and G. A. Balasubramaniam. 2017. Endoscopic evaluation of reticulum in cattle - A preliminary study. Indian Vet. J. 94:79-80.
Schoenfeld, P., B. Cash, A. Flood, R. Dobhan, J. Eastone, W. Coyle, J. W. Kikendall, H. M. Kim, D. G. Weiss, T. Emory, and A. Schatzkin. 2005. Colonoscopic screening of average-risk women for colorectal neoplasia. N. Engl. J. Med. 352:2061-2068.

Steele, M. A., J. Croom, M. Kahler, O. AlZahal, S. E. Hook, K. Plaizier, and B. W. McBride. 2011. Bovine rumen epithelium undergoes rapid structural adaptations during grain-induced subacute ruminal acidosis. Am. J. Physiol. Regul. Integr. Comp. Physiol. 300:R1515-R1523.

Steele, M. A., G. B. Penner, and F. Chaucheyras-Durand. 2016. Development and physiology of the rumen and the lower gut: Targets for improving gut health. J. Dairy Sci. 99:4955-4966.

Warner, R. G., W. P. Flatt, and J. K. Loosli. 1956. Ruminant nutrition, dietary factors influencing development of ruminant stomach. J. Agric. Food Chem. 4:788-792.

Washabau, R. J., M. J. Day, M. D. Willard, E. J. Hall, A. E. Jergens, J. Mansell, T. Minami, and T. W. Bilzer. 2010. Endoscopic, biopsy, and histopathologic guidelines for the evaluation of gastrointestinal inflammation in companion animals. J. Vet. Intern. Med. 24:10-26.

Wood, K. M., S. I. Palmer, M. A. Steele, J. A. Metcalf, and G. B. Penner. 2015. The influence of age and weaning on permeability of the gastrointestinal tract in Holstein bull calves. J. Dairy Sci. 98:7226-7237.

Zimin, A. V., A. L. Delcher, L. Florea, D. R. Kelley, M. C. Schatz, D Puiu, F. Hanrahan, G. Pereta, C. P. Van Tassell, T. S. Sonstegard, G. Marcias, M. Roberts, P. Subramanian, J. A. Yorke, and S. L. Salzberg. 2009. A whole-genome assembly of the domestic cow, Bos taurus. Genome Biol. 10:R42. 